\title{
Bilimin Rehberinden Bilginin Elitine
}

\section{From the Guide of Science to the Elite of Knowledge}

\section{Tayfun Gülle*}

This is a farewell editorial that summarizes the developments last decade of the journal also offers some suggestions for the future perspective due to leave the post of editor-in-chief.

\section{Merhaba Değerli Okur,}

Bütün zamanların en büyük bilim insanlarından Albert Einstein özlü sözlerinden birinde “Eğitim gerçeklerin ögrretilmesi değildir! Düşünmek için aklın ĕgitilmesidir.” diyor. Çı̆̆ır açan çalışmalarıyla bilim tarihine yön vermiş bu bilim insanının, düşünmenin önemine, aklın eğitilmesiyle yaptığı vurgu elbette pozitif bilimin ipuçları hakkında fikir vermektedir. İnsanoğlunun sahip olduğu akıl sayesinde dünyayı etkileyerek, doğanın dengesini bozduğu ekosistemi değiştirdiği ve devamında doğal kaynakların azalarak, su ve toprak kirliliği, orman yangınları, karbon salınımı, kıtlık, savaş, küresel hastalıklar (pandemi) gibi yaşam koşullarının altüst edildiği bir döngüyle karşı karşıya kalındığı günümüz gerçeğidir. Küresel bir savaş halini çağrıştıran günümüzün olağanüstü gerçekliği karşısında bir bakıma tarihe tanıklık etmekteyiz. Acaba Einstein, yaklaşık yüzyıl önce aklın eğitilmediği zaman dünyanın ne hale geleceğini, düşünme yetisiyle desteklenmeden alınan kararların, daha açık bir ifadeyle pozitif bilim göz ardı edilerek yapılanların dünyayı felakete sürükleyeceğini öngörmüş olabilir miydi? ${ }^{1}$

Değerli Okur,

Bildiğiniz gibi pozitif bilimin gereksindiği özgür düşünce ortamında üretilen bilimsel çalışmaların rehberliğini akademik yayınlar üstlenmektedir. Bu yayınlar arasında en güncel bilgi kanalı kuşkusuz bilimsel süreli yayınlardır. Bu bağlamda, okuduğunuz editoryalde ülkemizin ve dünyanın en eski mesleki ve bilimsel dergilerinden olan Türk Kütüphaneciliği’nin yakın geçmişine ilişkin kısa bir final değerlendirmesi yapılarak dergi yönetimindeki nöbet değişimi hakkında bilgi verilmesi amaçlanmıştır.

\footnotetext{
* Türk Kütüphaneciliği Sorumlu Yazı İşleri Müdürü. E-posta: turkkutuphaneciligieditor@gmail.com Editor-in-Chief of Turkish Librarianship

${ }^{1}$ Bilim insanlığının yanı sıra filozofluğu ile de öne çıkan Albert Einstein, Out of my later years: The scientist, philosopher, and man portrayed through his own words (1950) başlıklı kitabında, atom bombalarının Hiroşima ve Nagazaki'ye atılmasından önce projede çalıştığı diğer bilim insanlarıyla bombalamayı durdurma girişimlerinin sonuç vermediğini belirterek pişmanlığını ifade etmiş ve dönemin ABD Cumhurbaşkanı Roosevelt'e yazdığı mektupta atom enerjisinin uzun bir süre insanlık için iyiliğe vesile olmayacağını belirtmiştir.
}

Editör görüşü: Einstein pişmanlığını belirtse de, iki yüz binden fazla insanın yaşamını kaybettiği, yüzbinlerce insanın yaralandığı, maddi ve manevi hasarlarının günümüzde de devam ettiği, 6 ve 9 Ağustos 1945 tarihlerinde Japonya'nın iki kentine atılan atom bombaları Einstein için büyük bir çelişkidir. 


\section{Değerli Okur,}

Ülkemizin bilgi ve belge yönetimi alanındaki sorunları inceleyen ve çözüm önerileri sunan özgün bilimsel ve mesleki yazıların yayımlandığı Türk Kütüphaneciliği dergisinin 60 yıllık değerlendirmesi dergimizin 60. yaşının kutlandığı 2012 yılında yapılmıştı. ${ }^{2}$ Bu defa yörüngesine girilen 70. yılın 1şığında Türk Kütüphaneciliği’nin yakın geçmişi ve gelecek perspektifi üzerinde durulacaktır. Bu bağlamda Türk Kütüphaneciliği'nin 60. yayın yılının kutlandığı 2012 yılından bu yana dergi kapsamında öne çıkan gelişmeler daha kolay anlaşılabilmesi için kronolojik olarak sıralanmıştır:

$\checkmark 2012$ y1lında Türk Kütüphaneciliği’nin 60 y1llık yayıncılık sürecini anlatan “Türk Kütüphaneciliği'nin 60. Y11 Belgeseli” çekildi,

$\checkmark 2012$ yılında Facebook sayfası (https://www.facebook.com/turkkutuphaneciligi) açıld1,

$\checkmark 2013$ yılında web sitesi dergi alan adı (www.tk.org.tr) üzerinden açıldı,

$\checkmark 2014$ yılında Yayın Kurulu, Editörler Kurulu olarak örgütlendi,

$\checkmark$ 3-5.09.2014 tarihinde Kastamonu Üniversitesi Bilgi ve Belge Yönetimi tarafından düzenlenen 1. Uluslararası Kütüphane ve Bilgibilim Felsefesi Sempozyumu kapsamında "Türk Kütüphaneciliğinde Bilimsel İletişim Sürecini İyileştirme Çalıştayı" düzenlendi,

$\checkmark 2014$ y1lında Kütüphaneciliğimize Kanat Gerenler ve Eleştiri (Critics) bölümleri açıld1,

$\checkmark 2014$ y1lında Editoryal Kontrol Formu, Telif Hakk1 Transfer Bildirimi, Makale Değerlendirme Formu oluşturuldu,

$\checkmark$ Kastamonu'da düzenlenen çalıştay sonrası 2015 y1lında meslektaşlarımıza Türk Kütüphaneciliği bilimsel iletişim sürecini değerlendiren anket uyguland1,

$\checkmark 2015$ yılı Haziran sayısı "Bilimsel İletişim Özel Sayısı” olarak yayımlandı,

$\checkmark 2015$ yılı Aralık sayısı "Düşünce Özgürlüğü Özel Sayısı" olarak yayımland1,

$\checkmark 2015$ y1lında APA 6 Kuralları klavuzu basılı ve elektronik formatta yayımland,

$\checkmark 2015$ yılında Türk Kütüphaneciliği WoS (Clarivate Analytics) / ESCI veritabanında dizinlenmeye başladı,

$\checkmark$ 15.04.2016 tarihinde Ankara Üniversitesi ev sahipliğinde WoS dönemecinde yeni süreçlere ilişkin bilgi paylaşımında bulunmak üzere "Türk Kütüphaneciliğinde Yeni Bir Dönemeç Forumu” düzenlendi,

$\checkmark 2016$ yılında kurumsal yapıyı güçlendirmek için Türk Kütüphaneciliği Yönetim Belgesi (http://tk.org.tr/belgeler/TK-Yonetim_Belgesi.pdf) hazırland1,

$\checkmark 2016$ yılında Editörler Kurulu'na danışman üye atandı,

$\checkmark 2017$ yılında APA Kuralları klavuzunun ikinci basımı (http://tk.org.tr/APA/apa_2.pdf) yayımland1,

$\checkmark 2017$ yılında derginin bilimsel bölümü, Araştırma makaleleri (Research), Kavramsal makaleler (Theoretical), Örnek Olay çalışmaları (Case Study), Literatür Değerlendirme makaleleri (Literature Review) olarak kategorize edildi,

\footnotetext{
${ }^{2}$ Gülle, M. T. (2012). Türk Kütüphaneciliği’nin 60 Yılı. Türk Kütüphaneciliği, 26(4), 641-653. Erişim adresi http://www.tk.org.tr/index.php/TK/article/view/2469/2472
} 
$\checkmark 2017$ yılında makalelere DOI (Digital Object Identifier) numarası verilmeye başladı,

$\checkmark 2017$ y1lında yeni logo tasarland,

$\checkmark 2017$ yılında iç kapaktaki hakem listesinde son 3 yılda değerlendirme yapan hakemlerin isimleri yer almaya başladı,

$\checkmark 2018$ y1lında twitter hesabı (@turkkutup1952) açıld1,

$\checkmark 2018$ yılında Haberler ve Mesleki Toplantılar bölümleri kaldırıldı, bunların yerine haber değeri taşıyan konularda okuyucu mektupları ve mesleki toplantılara katılım sağlayan meslektaşların mektup niteliğindeki yazıları yer almaya başladı,

$\checkmark 2018$ yılı Aralık sayısı Doç. Dr. Mustafa Akgül anısına “Bilişim Özel Sayısı” olarak yayımland1,

$\checkmark 2019$ y1lında Araştırma Değerlendirme Üzerine San Francisco Deklarasyonu'na (DORA) katılım sağland1,

$\checkmark 2019$ yılında Türk Kütüphaneciliği sadece elektronik formatta yayımlanmaya başladı,

$\checkmark 2019$ yılında DergiPark barındırma sistemine dahil olundu,

$\checkmark 2019$ yılında Creative Commons - Atıf Gayri Ticari 4.0 Uluslararası Lisansı uygulaması başladı,

$\checkmark 2019$ yılı Aralık sayısı "Türkiye'de Kütüphanecilik” temasıyla Prof. Dr. Meral Alpay anısına özel sayı formatında yayımland1,

$\checkmark 2020$ yılı Mart sayıs1 "Kütüphaneciliğimize Kanat Gerenler I" temasıyla Prof. Dr. Necmeddin Sefercioğlu anısına özel sayı formatında yayımlandı,

$\checkmark 2020$ yılı Haziran sayısı "Kütüphaneciliğimize Kanat Gerenler II" temasıyla Prof. Dr. Berin U. Yurdadoğ anısına özel sayı formatında yayımlandı,

$\checkmark 2020$ yılı Eylül sayısı ile erken görünüm uygulamasına başlandı,

$\checkmark$ 2013-2020 yılları arasında 5.170 sayfadan oluşan 36 sayıda 489 makale yayımlandı (1952-2020 yılları arasında 30.000'i aşkın sayfadan oluşan 276 sayıda 2.843 makale yayımland1),

$\checkmark 2020$ y1l itibariyle toplam hakem sayısı $108^{\prime}$ dir,

$\checkmark 2020$ yılı itibariyle 7 editör, 8 editör yardımcısı olmak üzere Editörler Kurulu sayısı 15 kişidir,

$\checkmark 2021$ y1lında Yönetim Belgesi güncellendi.

Değerli Okur,

Türk Kütüphaneciliği’nin 69. y1lına kadar katettiği mesafe, hitap ettiği disiplinin devingen yapısı dikkate alındığında yeterli görülmeyebilir. Ülkemizde bilimsel yayıncılığın kısmen kurumsallaşmış yapısı elbette Türk Kütüphaneciliği'ni de etkilemekte, editörlük mekanizmasının zaman zaman noter gibi algılanmasına neden olmaktadır. Bu yanlış algıda bilimsel iletişimin ana aktörleri olan yazar, editör, hakem üçlüsünün karşılıklı empati kurgusundaki yetersizliğin payı büyüktür. Bu farkındalıkla Türk Kütüphaneciliği Editörler Kurulu olarak süreçteki sorunların önemli bir bölümünü editoryal müdahalelerle çözüme kavuşturmaya çalışıyoruz. Bu durumda editoryal iletişim doğal olarak bilimsel iletişimde lokomotif role sahip olmaktadir. 
Değerli Okur,

Meslek yayınlarımızın çınarı olarak, hitap ettiği disiplinde bilimsel rehber olma iddiasındaki Türk Kütüphaneciliği, giderek kurumsallaşan yönetim yapısı ve sahip olduğu teknolojik donatı ile geleceğe güvenle bakmaktadır. Diğer taraftan, Türk Kütüphaneciliği içerik yönetimindeki yenilik arayışları ile nitelikli yayın üretiminin teşvik edildiği, akademik değer kazandırıcı olarak bilginin eliti olmak zorundadır. Bu zorunluluk Türk Kütüphaneciliği'nin tarihsel misyonu gereği olup, orta vadede daha üst veritabanlarında taranır ve görünür olmasıyla yakından ilişkilidir.

Değerli Okur,

Oldukça uzun soluklu ve hiç bitmeyecekmiş gibi görünen Türk Kütüphaneciliği Sorumlu Yazı İşleri Müdürlüğü görevi benim açımdan hem bir okul hem de ekol olmuştur. 2008 y1lında başlayan bu sürecin sonunu hoşça kalın diyerek bitirmek yerine yine Einstein'ın kulaklara küpe, veciz bir sözüyle tamamlamak anlamlı görünüyor; "Kesinlikle bilmek zorunda olduğunuz tek bilgi kütüphanenin nerede olduğudur." 